\title{
PENERAPAN JARINGAN SARAF TIRUAN PADA DATA GEMPA BUMI DI PROVINSI BENGKULU
}

\author{
Winalia Agwil $^{1}$, Pepi Novianti ${ }^{2}$, Nurul Hidayati ${ }^{3}$ \\ 1,2,3 Universitas Bengkulu, Jl. W. R. Supratman, Bengkulu 38125, Indonesia \\ Email : winaliaagwil@unib.ac.id
}

\begin{abstract}
ABSTRAK
Provinsi Bengkulu merupakan wilayah yang sangat dekat dengan subduksi lempeng Eurasia dan Indo-Australia, hal ini mengakibatkan provinsi Bengkulu menjadi daerah yang rawan terjadinya bencana gempa bumi. Prediksi mengenai banyak kejadian dan rata-rata magnitudo gempa sangat menarik untuk di teliti. Penelitian mengenai analisis gempa bumi telah banyak dilakukan salah satunya dengan metode data mining yaitu Jaringan Saraf Tiruan. Tujuan dari penelitian ini adalah memperoleh arsitektur jaringan terbaik yang diterapkan pada data frekuensi kejadian dan rata-rata magnitudo gempa bumi per bulan di Provinsi Bengkulu. Kriteria pemilihan arsitektur jaringan terbaik dilakukan dengan membandingkan nilai RMSE dan MAE setiap kemungkinan arsitektur yang terbentuk. Hasil prediksi rata-rata magnitudo per bulan yang dimodelkan dengan arsitektur 1-3-1 lebih baik dibandingkan dengan arsitektur 12-3-1.
\end{abstract}

Kata Kunci: Bengkulu, Jaringan Saraf Tiruan, Gempa Bumi, RSME, MAE.

\section{PENDAHULUAN}

Provinsi Bengkulu merupakan salah satu daerah yang terletak di pesisir barat Pulau Sumatera yang secara geografis berbatasan langsung dengan Samudra Hindia. Subduksi (tumbukan) pertemuan lempeng Eurasia dan Indo-Australia berada di bagian timur Samudra Hindia atau sekitar 150 KM dari Provinsi Bengkulu. Gerakan yang diakibatkan kedua lempeng tersebutmenimbulkan terjadinya patahan aktif yang merupakan generator seismisitas di belahan Sumatera.Selain itu, Bengkulu juga berada diantara dua patahan aktif yakni patahan Semangko dan Mentawai yang menjadikan Provinsi Bengkulu dan sekitarnya sebagai wilayah yang rawan terjadi gempa bumi.

Menurut penelitian yang dilakukan [6] disimpulkan bahwa gempa bumi yang terjadi di wilayah Sumatera cenderung memiliki frekuensi yang cukup tinggi dengan nilai rata-rata kekuatan gempa mencapai 5 SR dan lokasi kejadian berada di laut. Demikian juga hasil penelitian [4] bahwa secara umum kejadian gempa di provinsi Bengkulu memiliki pusat di laut dengan frekuensi kejadian lebih dari 5 kali dalam setiap bulan dengan lokasi sekitaran pulau Enggano. Hal ini menjadi menarik untuk dikaji sebagai bentuk upaya mengurangi kerusakan yang diakibatkan oleh kejadian gempa yang berlokasi di laut dan bisa saja mengakibatkan tsunami. Oleh karena itu, diharapkan terdapat beberapa metode statistika yang dapat menggambarkan hubungan atau pola-pola kejadian gempa tersebut sehingga dapat meprediksi kejadian gempa jangka pendek.

Upaya memodelkan kejadian gempa dengan menggunakan metode-metode dalam data mining sudah banyak dilakukan oleh peneliti, salah satunya dengan menggunakan Jaringan Saraf Tiruan (JST) yang dianggap sanggup membaca pola 
hubungan antar variabel dalam data. Menurut [11] metode Jaringan Saraf Tiruan dapat memprediksi rata-rata Gempa Bumi di wilayah Maluku Utara pada bulan/periode berikutnya dibandingkan metode ARIMA sedangkan [2] berpendapat bahwa metode Jaringan Saraf Tiruan dengan menggunakan algoritma Multilayer Percepton dapat meramalkan kekuatan gempa dengan akurasi tinggi.

\section{Data Mining}

Data mining merupakan terapan ilmu yang mempelajari metode untuk mendapatkan pengetahuan atau menemukan pola hubungan suatu data [9]. Dalam data mining membutuhkan beberapa terapan ilmu seperti ilmu komputer, machine learning, matematika dan statistika. Proses kerja dalam data mining adalah melakukan pencarian secara berulang (iterative) dan intensif yang bertujuan untuk mengekstrak pengetahuan dari sekumpulan data yang sebelumnya memiliki arti penting. Pengetahuan yang dimaksud dapat berupa pola/pattern, hubungan, perubahan, anomaly, struktur, rumus, aturan ataupun model yang muncul dari data [9]. Secara umum terdapat 5 (lima) peran utama data mining, yaitu :
1. Estimasi
2. Prediksi
3. Klasifikasi
4. Pengelompokkan (clustering)
5. Asosiasi

Metode yang popular digunakan dalam data mining, antara lain metode Jaringan Saraf Tiruan (Artificial Neural Network).

\section{Jaringan Saraf Tiruan}

Jaringan Saraf tiruan merupakan metode komputasi dalam data mining yang didesain untuk mengenali pola, signal processing dan peramalan yang dasarnya meniru proses jaringan Saraf biologis dalam otak [10]. Layaknya jaringan Saraf biologis manusia didalam jaringan Saraf tiruan juga terdapat sel Saraf (neuron) yang saling terhubungan antara neuron yang satu dan lainnya. Neuron/selSaraf adalah sebuah unit yang didesain untuk melakukan proses informasi yang merupakan dasar operasi Jaringan Saraf Tiruan [8].

Terdapat tiga hal yang harus diperhatikan dalam Jaringan Saraf Tiruan:

a. Pola hubungan antar neuron (disebut arsitektur jaringan). Arsitektur jaringan yang digunakan dalam JST, sebagai berikut :

1. Single Layer Network (Jaringan Lapis Tunggal).

Jaringan lapis tunggal ini memiliki sekumpulan layer input yang dihubungkan secara langsung dengan layer output, sehingga dalam beberapa model hanya memiliki satu layer output. Gambarnya sebagai berikut :

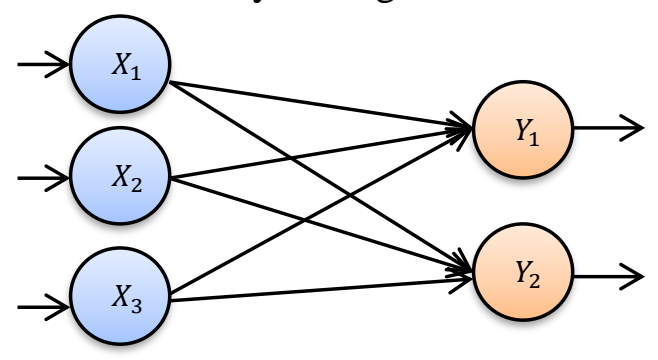

Gambar 1. Single Layer Network

2. Multi Layer Network (Jaringan Lapis Jamak)

Jaringan lapis jamak memiliki beberapa layer input dan layer output dan juga memiliki layer tersembunyi (hidden layer).

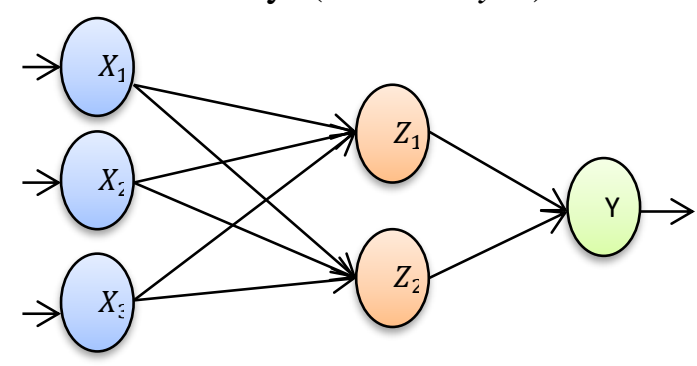

Gambar 2. Multi Layer Network 
b. Metode untuk menentukan bobot penghubung (metode learning/training). Bobot penghubung yang digunakan ada dua, yaitu unsupervised adalah bobot terbentuk berdasarkan input yang diberikan tanpa ditentukan pencapaian targetnya dan supervised learning bobot yang terbentuk sesuai input yang diberikan dan target yang ingin dicapai.

c. Fungsi aktivasi digunakan untuk mengaktifkan dan menonaktifkan neuron [5].

\section{Model Jaringan Saraf Tiruan}

Misalkan terdapat $x_{i}$ dimana $i=1, \ldots, n$ merupakan variabel input yang akan digunakan untuk menduga $\hat{y}_{k}$ dengan $k=$ $1, \ldots, p$ maka interpolasi Neural Network dapat digambarkan dalam persamaan berikut [10]:

$\hat{y}_{k}=f^{o}\left[\sum_{j=1}^{m}\left(w_{j} f_{j}^{h}\left(\sum_{i=1}^{n} v_{j i} x_{i}(k)+v_{o j}\right)+w_{o}\right)\right]$

dengan,

$\hat{y}_{k}:$ Nilai output

$x_{i}$ : Variabel input

$f^{o}$ : Fungsi aktivasi

$f_{j}^{h}$ : Fungsi aktivasi neuron ke-j pada

hidden layer

$w_{j}$ : Bobot antara hidden layer dan output layer layer

$v_{j i}$ : Bobot antara input layer dan hidden

$w_{o}$ : Bias pada neuron output

$v_{o j}$ : Bias neuron ke-j pada hiddenlayer

\section{Algoritma Back Propagation}

Tahapan dalam algoritma ini dimulai dengan prosedur propagasi maju yaitu:

1. Inisialisasi bobot awal

2. Untuk setiap data input pada data pelatihan (training), hitung nilai $h_{i}$ dengan menggunakan nilai input dan bobot yang berelasi.

$$
h_{j}=\sum_{i=1}^{n} w_{i j} x_{i}+v_{0 j}
$$

$h_{j}=$ input pada neuron $\mathrm{ke}-\mathrm{j}$ pada hidden layer

$w_{i j}=$ bobot relasi dari input ke-i yang terhubung ke neuron ke-j pada hidden layer

$x_{i}=$ input ke $-\mathrm{i}$

3. Berdasarkan input yang diperoleh dari tahap 2. Hitung ouput neuron ke-j pada hidden layer dengan menggunakan fungsi aktifasi:

$$
\text { out } h_{j}=\frac{1}{1-e^{-h_{j}}}
$$

4. Hitung input pada layer output:

$$
y_{i}=\sum_{j=1}^{m} w_{j} * \text { out } h_{j}+w_{0}
$$

5. Hitung output pada layer output:

$$
\text { out } y_{j}=\frac{1}{1-e^{-y_{j}}}
$$

6. Hitung nilai Error antara nilai yang diprediksi dengan nilai yang sesungguhnya dengan rumus:

$$
\begin{gathered}
\text { Error }_{j}=\text { out } y_{j} \\
*\left(1-\text { out } y_{j}\right) \\
*(\text { target } \\
\left.- \text { out } y_{j}\right)
\end{gathered}
$$

out $y_{j}$ merupakan nilai y yang diperoleh dari simpul $\mathrm{j}$ dan target $_{j}$ adalah nilai target yang telah diketahui pada data training.

7. Setelah nilai Error dihitung, selanjutnya kembali ke layer sebelumnya untuk menghitung nilai Error pada hidden layer dengan menggunakan rumus:

$$
\begin{aligned}
& \text { Error }_{j} \\
& =\text { out } y_{j}\left(1-\text { out } y_{j}\right) \sum_{k=1}^{n} \text { Error }_{k} w_{j k}
\end{aligned}
$$

8. Update bobot dengan menggunakan Error $_{j}$ yang diperoleh pada tahap 7 dan learning rate $(l)$ :

$$
w_{i j}=w_{i j}+l * \text { Error }_{j} * \text { out } y_{j}
$$

\section{Evaluasi Model}

Model yang baik dapat memberikan galat yang kecil terhadap nilai sebenarnya. Evaluasi kebaikan model dalam 
memprediksi dapat diukur menggunakan mean square error (MSE) [7].

$$
\begin{aligned}
& M S E=\frac{1}{n} \sum_{i=1}^{n}\left(y_{i}-\hat{f}\left(x_{i}\right)\right)^{2} \\
& R M S E=\sqrt{M S E} \\
& M A E=\frac{1}{n} \sum_{i=1}^{n}\left|y_{i}-\hat{f}\left(x_{i}\right)\right|
\end{aligned}
$$

$y_{i}$ merupakan data aktual dan $\hat{f}\left(x_{i}\right)$ adalah niai hasil peramalan dengan metode tertentu. Model yang baik adalah model yang memberikan nilai MSE, RMSE dan MAE paling kecil.

\section{METODE PENELITIAN}

\section{Sumber Data}

Data yang digunakan dalam penelitian ini adalah data sekunder terjadinya gempa di Provinsi Bengkulu dari Januari 2010 sampai dengan Agustus 2019, yang diperoleh dari USGS yang diakses melalui web: https://earthquake.usgs.gov/ dan akan dibagi menjadi dua bagian. Kelompok data pertama yaitu data Januari 2010 sampai Desember 2017 digunakan sebagai data latih. Data kedua adalah data Januari 2018 sampai dengan Agustus 2019 digunakan sebagai data uji.

\section{Metode Analisis}

Adapun langkah-langkah yang dilakukan dalam penelitian ini adalah :

1. Eksplorasi data gempa bumi yang terjadi di provinsi bengkulu

a. Membuat plot rata-rata kekuatan gempa per bulan

b. Membuat plot banyak kejadian gempa per bulan

2. Membagi data menjadi 2 bagian yakni data latih dan data uji

3. Data latih digunakan untuk membangun model dengan menggunakan Jaringan Saraf Tiruan (JST), setiap kemungkinan parameter di modelkan seperti jumlah hidden layer, jumlah input.

4. Memodelkan data uji dengan hasil model Jaringan Saraf Tiruan (JST) yang diperoleh dari proses pada data latih.

5. Melakukan evaluasi model dengan menggunakan RMSE dan MAE untuk setiap kemungkinan model yang dapat di bentuk dengan metode Jaringan Saraf Tiruan.

\section{HASIL DAN PEMBAHASAN}

Kurun waktu Januari 2010 sampai dengan Agustus 2019, frekuensi kejadian gempa tertinggi terjadi pada bulan Oktober 2010 yakni terdapat 45 kali kejadian gempa bumi. Sedangkan dari awal tahun 2012 banyaknya kejadian gempa per bulan masih di bawah 10 (Gambar 3) dengan rata-rata magnitudo perbulan berada pada selang nilai 4 - 5 SR (Gambar 4).

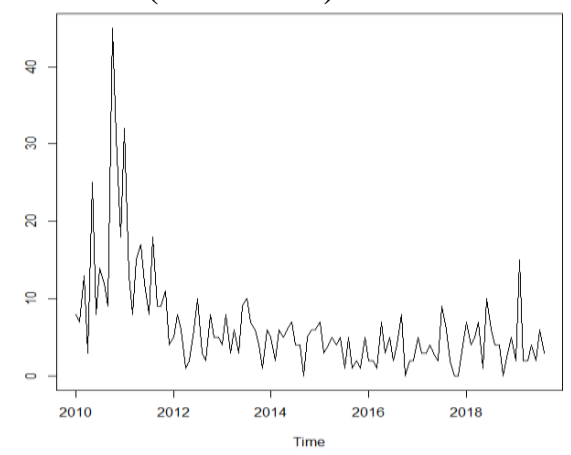

Gambar 3. Banyak Kejadian Gempa perbulan di Provinsi Bengkulu

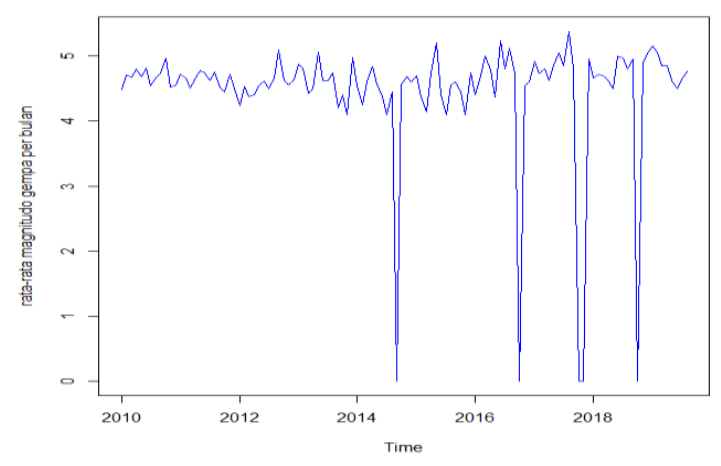

Gambar 4. Rata-Rata Magnitudo Gempa perbulan di Provinsi Bengkulu 


\section{Jaringan Saraf Tiruan pada Data Training}

Data deret waktu yang digunakan dalam penelitian ini berjumlah 116 observasi yang dibagi menjadi 97 observasi sebagai data training (pelatihan) dan 19 observasi sebagai data testing (pengujian). Pada data training dilakukan proses pembelajaran Jaringan Saraf Tiruan yang mengatur input, bobot dan juga bias. Tabel 2 menyajikan beberapa kombinasi jumlah input dan jumlah neuron pada hidden layer yang diterapkan pada data training (pelatihan) banyak kejadian gempa per bulan dan nilai RMSE dan MAE masing-masing kombinasi.

Tabel 1. Pelatihan Data Banyak Kejadian Gempa

\begin{tabular}{c|c|c|c|c}
\hline & $\begin{array}{c}\text { Jumlah } \\
\text { Input }\end{array}$ & $\begin{array}{c}\text { Neuron Hidden } \\
\text { Layer }\end{array}$ & $\begin{array}{c}\text { RMSE } \\
\text { Train }\end{array}$ & $\begin{array}{c}\text { MAE } \\
\text { Train }\end{array}$ \\
\hline NN2 & 7 & 4 & 2,09 & 2,11 \\
NN3 & 7 & 2 & 2,62 & 2,08 \\
NN4 & 9 & 6 & 1,732 & 1,2 \\
NN5 & 8 & 10 & 1,43 & 1,06 \\
NN6 & 7 & 2 & 2,44 & 1,97 \\
NN7 & 5 & 7 & 1,94 & 1,44 \\
NN8 & 6 & 2 & 2,71 & 2,14 \\
NN9 & 8 & 7 & 1,79 & 1,27 \\
NN10 & 2 & 5 & 3,18 & 2,39 \\
NN11 & 6 & 1 & 3,32 & 2,39 \\
NN12 & 4 & 2 & 3,32 & 2,39 \\
NN13 & 5 & 1 & 3,27 & 2,56 \\
NN14 & 5 & 1 & 3,06 & 2,4 \\
\hline
\end{tabular}

Arsitektur Jaringan Saraf Tiruan yang memberikan RMSE dan MAE terkecil dari beberapa kombinasi jumlah input dan jumlah neuron pada hidden layer yang dicobakan secara trial and error yaitu 8 Input (lag 1,3,4,6,7,9,10,12) dan 10 neuron Hidden layer (Tabel 1).

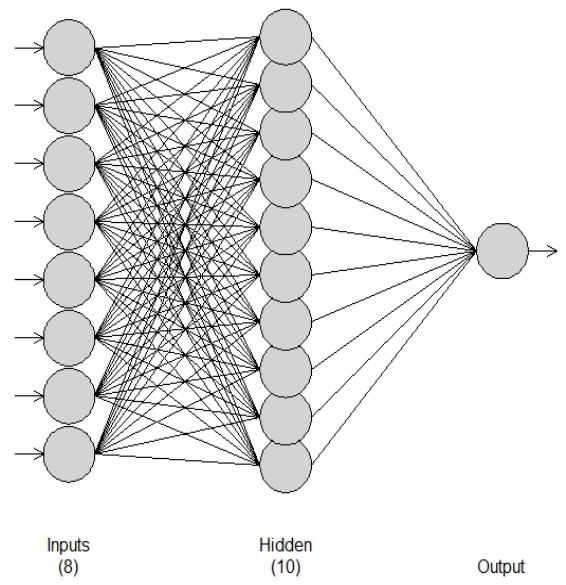

Gambar 5. Arsitektur Neural Network

Tabel 2 menyajikan beberapa kombinasi jumlah input dan jumlah neuron hidden layer yang diterapkan pada data training rata-rata magnitudo per bulan, selain itu terdapat nilai RMSE dan MAE masingmasing kombinasi.

Tabel 2. Pelatihan Data Rata-Rata Magnitudo Gempa

\begin{tabular}{ccccc}
\hline & $\begin{array}{c}\text { Jumlah } \\
\text { Input }\end{array}$ & $\begin{array}{c}\text { Hidden } \\
\text { Layer }\end{array}$ & $\begin{array}{c}\text { RMSE } \\
\text { Train }\end{array}$ & $\begin{array}{c}\text { MAE } \\
\text { Train }\end{array}$ \\
\hline NN2 & 3 & 2 & 0,76 & 0,36 \\
NN3 & $\mathbf{1 2}$ & $\mathbf{3}$ & $\mathbf{0 , 1 8 8}$ & $\mathbf{0 , 1 3}$ \\
NN4 & 7 & 3 & 0,377 & 0,235 \\
NN5 & 5 & 1 & 0,944 & 0,5 \\
NN6 & 3 & 1 & 0,93 & 0,52 \\
NN7 & 5 & 2 & 0,6 & 0,3 \\
NN8 & 3 & 4 & 0,7 & 0,35 \\
NN9 & 4 & 1 & 1,044 & 0,55 \\
NN10 & 3 & 1 & 1,055 & 0,56 \\
NN11 & 5 & 5 & 0,27 & 0,19 \\
NN12 & 3 & 1 & 0,27 & 0,196 \\
NN13 & 3 & 5 & 0,56 & 0,29 \\
NN14 & 1 & 3 & 1,02 & 0,5 \\
\hline
\end{tabular}

Arsitektur terbaik pada proses pelatihan adalah dengan kombinasi input 12 (lag 112) dan dan 3 hidden layer, hal ini terlihat dari nilai RMSE dan MAE terkecil. Gambar 4 merupakan gambaran arsitektur 
Jaringan Saraf Tiruan dengan 12 input dan 3 neuron hidden layer.

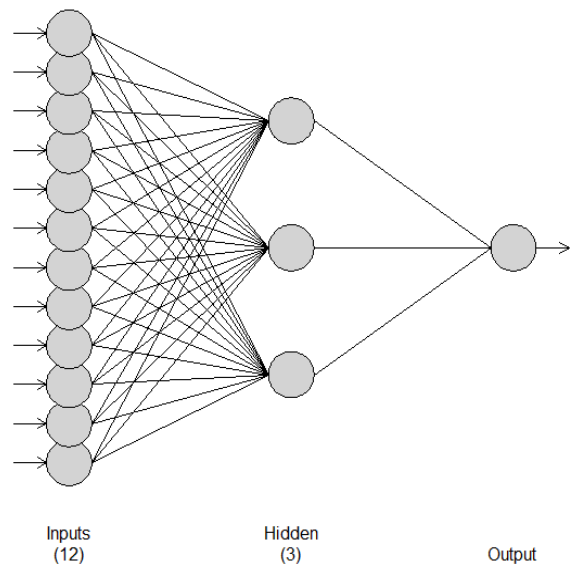

Gambar 6. Arsitektur 12-3-1

\section{Pengujian}

Tahap selanjutnya adalah memprediksi banyaknya kejadian gempa bumi per bulan dan rata - rata magnitudo gempa bumi per bulan di Provinsi Bengkulu dan sekitar dengan memanfaatkan arsitektur yang telah diperoleh dari proses pembelajaran (learning) dan kemudian diterapkan pada data testing. Pengujian dilakukan untuk melihat performa arsitektur terpilih pada data yang baru. Performa arsitektur jaringan saraf tiruan yang baik dapat dilihat dari error yang kecil atau dapat dilihat dari pola prediksi yang mirip dengan data asli (aktual).

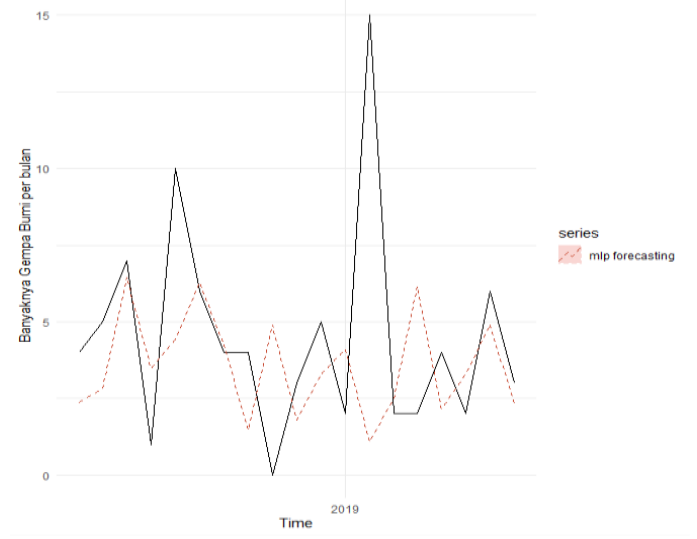

Gambar 7. Perbandingan Data Testing dan Prediksi dengan Arsitektur 8-10-1
Gambar 7 menunjukkan perbandingan antara data asli (aktual) frekuensi gempa per bulan dengan data prediksi. Grafik perbandingan menunjukkan bahwa hanya di beberapa titik observasi saja yang memiliki nilai hampir mendekati dan jika dilihat dari plot belum terlalu baik. Demikian juga hal nya dengan Gambar 8 yang menggambarkan perbandingan data aktual dan prediksi rata-rata gempa bumi per bulan, terlihat bahwa pola data aktual dan data prediksi sangat jauh berbeda.

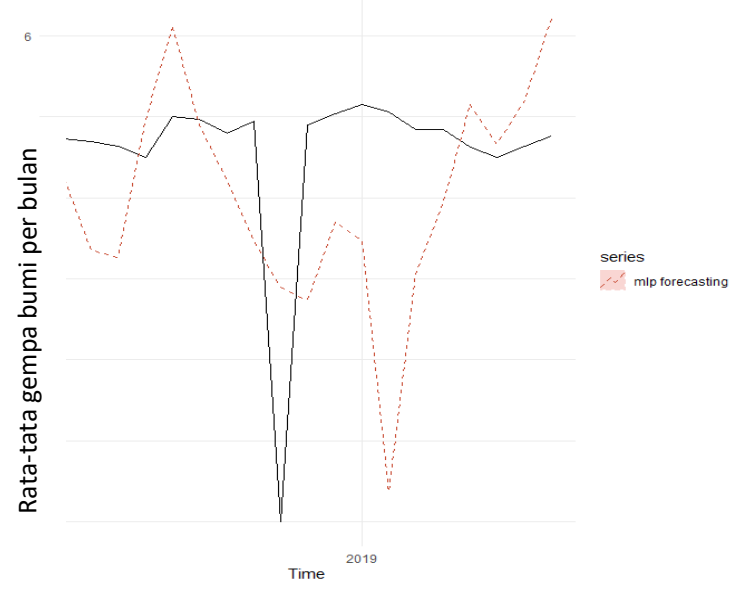

Gambar 8. Perbandingan data aktual dan prediksi dengan Arsitektur 12-3-1

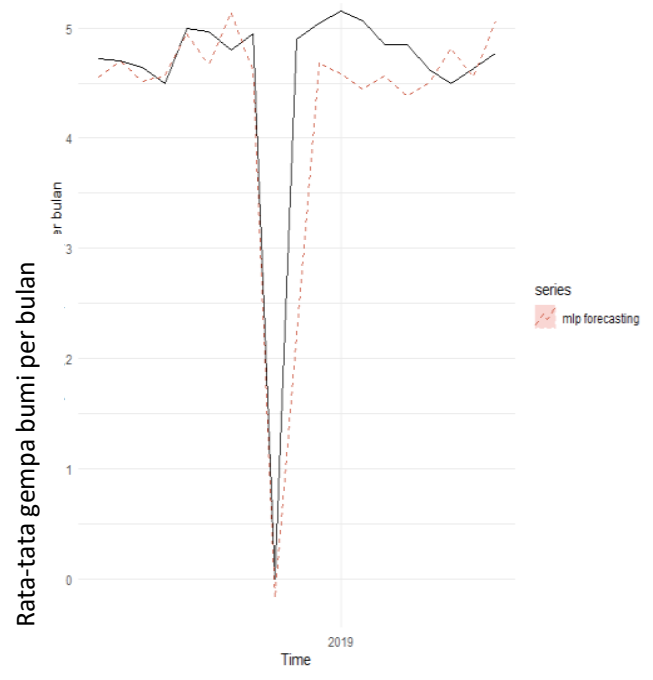

Gambar 9. Perbandingan Data Testing dan Prediksi dengan Arsitektur 1-3-1 
Prediksi rata-rata magnitudo per bulan lebih baik di modelkan dengan arsitektur 13-1 dibangdingkan dengan arsitektur 12-31, hal ini terlihat jelas dengan membandingkan gambar 8 dan gambar 9 . Pada Gambar 9 dapat dilihat bahwa data prediksi hampir mendekati data aktual.

\section{KESIMPULAN}

Adapun kesimpulan dalam penelitian ini:

1. Berdasarkan proses pelatihan pada data banyak kejadian gempa diperoleh bahwa arsitektur yang memiliki RMSE dan MAE terkecil adalah arsitektur dengan 8 input, 10 neuron hidden layer dan 1 output.

2. Berdasarkan proses pelatihan pada data rata-rata magnitudo gempa diperoleh bahwa arsitektur yang memiliki RMSE dan MAE terkecil adalah arsitektur dengan 12 input, 3 neuron hidden layer dan 1 output.

3. Data testing rata-rata magnitudo gempa bumi per bulan perbulan lebih baik di modelkan dengan arsitektur dengan 1 input (lag 12), 3 neuron hidden layer dan 1 output.

\section{DAFTAR PUSTAKA}

[1] Bhatia, A. Sumantra, P and Anand, F. 2018. Earthquake Forecasting using Artificial Neural Networks. The International Archives of the Photogrammetry, Remote Sensing and Spatial Information Sciences, Volume XLII-5

[2] Elnashai, A. S and Sarno, L. D. 2008. Fundamentals of Earthquake Engineering.Wiley: California.

[3] Faisal, F. Pepi, N dan Rizal, J. 2017. Aplikasi Analisis Gerombolan dan Visualisasi Multidimensional Gempa Bumi di Provinsi
Bengkulu dan Sekitarnya. SEMIRATAnet : Manado.

[4] Hatie, T. Robert ,T. and Jerome, F. 2008. A element of Statistical Learning. Willey : California

[5] Irwanto, A. Nugroho, S. Rizal, J. 2014. Penggunaan Model AFRIMA untuk Peramalan Gempa Tektonik di Wilayah Sumatera. Skripsi

[6] James, G. Daniella, W. Trevor, H. and Robert, T. 2013. An Introduction of Statistical Learning. Springer :New York.

[7] Kulahci, F. and Z. Sen. 2008. Multivariate statistical analyses of artificial radionuclides and heavy metals contaminations in deep mud of Keban Dam Lake, Turkey, Appl. Radiat. Isot., vol. 66, pp. 236-246.

[8] Pramana, S. Budi, Y. Siti, M. Ibnu, S. dan Rani, N. 2018. Data Mining dengan R. In Media : Bogor.

[9] Siang, J. J. 2005. Jaringan Saraf Tiruan dan Pemrogramannya Menggunakan Matlab. Penerbit Andi: Yogyakarta.

[10] United States Geological Survey. Diakses melalui web USGS: https://earthquake.usgs.gov/.

Diakses pada tanggal 17 juli 2019 pukul 11.35.

[11] Sultan, H. M. 2014. Optimasi Parameter Neural Network pada Data Time Series untuk Memprediksi Rata-Rata Kekuatan Gempa Per Periode (Studi Kasus Gempa Bumi di Maluku Utara). Cauchy: Vol 3 N0.2. 